\title{
LA REFORMA URGENTE Y PARCIAL DEL CODIGO PENAL Y LA REDENCION DE PENAS POR EL TRABAJO
}

Luis GARRIDO GUZMAN

Profesor Adjunto de Derecho Penal

SUMARIO:

1.- Concepto y naturaleza de la redención de penas por el trabajo.

2.-Evolución normativa.

3.-El artículo 100 del Código penal después de la reforma urgente y parcial de 1983:
A) Condiciones generales para su concesión.
B) Ambito de aplicación.
C) Causas de incapacidad.
D) Iniciación.
E) Clases y efectos de la redención.
F) Supuestos excepcionales de redención sin actividad laboral.
G) Pérdida de redención.
H) Control judicial.

4.-La redención de penas por el trabajo y los beneficios penitenciarios. 

1.-Concepto y naturaleza juridica de la redención de penas por el trabajo(1).

Podemos definir la redención de penas por el trabajo como una institución de prevención especial que sirve para acortar el tiempo de duración de la condena de aquellos sentenciados que desempeñen básicamente una actividad laboral en un centro penitenciario y cumplan los requisitos que establece el Código penal.

En cuanto a la naturaleza jurídica de la redención de penas se plantean, esencialmente, dos problemas. El primero de ellos, relativo a la duración de la condena, hay autores que consideran que la redención se puede encuadrar dentro del ámbito de la sentencia indeterminada. Y así, ANTON ONECA(2) afirma que se trata en realidad de una encarnación del sistema progresivo bajo régimen de sentencia indeterminada. En el mismo sentido, DEL ROSAL(3) opina que la redención, conjugada con la libertad condicional, da entrada, en buena medida, a la sentencia indeterminada, o al menos deja depender del comportamiento del reo la mayor o menor privación de libertad: las llaves de la cárcel las tiene el recluso en sus manos a través de la redención de penas por el trabajo. Sin embargo, y a pesar del parentesco que mantienen ambas instituciones, BUENO ARUS(4) afirma que la normativa vigente es suficientemente expresiva sobre la naturaleza jurídica de la institución. El Reglamento de los Servicios de Instituciones Penitenciarias de 1956 dispuso en su artículo 66: «Al recluso trabajador se le abonará un día de su pena por cada dos de trabajo, a efectos de su libertad definitiva...". En el mismo sentido se pronuncia el texto del Código penal vigente: "Al recluso trabajador se abonará, para el cumplimiento de la pena impuesta..., un día por cada dos de trabajo...". A mayor abundamiento, el artículo 220 del Reglamento citado permitía la redención en quienes ya se encuentran en la situación de libertad condicional, "a efectos de acelerar la obtención de su libertad definitiva". Incluso una nota oficiosa del propio Ministerio de Justicia declaraba que ueste tiempo de redención es de la misma naturaleza que el tiempo de cumplimiento de la condena, pues ambos dan lugar a la extinción de éste, sin que por consiguiente, cualquiera que fuese la conducta del liberado, sea posible privarle del tiempo redimido por el trabajo...»(5). A la vista de estos textos legales, afirmamos con BUENO ARUS(6) que la redención de penas por el trabajo, es esencial- 
mente extinción (parcial) de la responsabilidad criminal, y, más concretamente, cumplimiento de la condena (art. 112-2. ${ }^{a}$ del Código penal). La redención constituye, en definitiva, a nuestro entender, un medio de liberación, puesto que el penado, por medio de la actividad laboral, puede liberarse de una parte de la condena. Liberación o cumplimiento que no sólo afecta a la pena privativa de libertad, sino también a las accesorias correspondientes, como dispuso la Orden de 6 de febrero de 1956: "Artículo único. Que la redención de penas por el trabajo, que regula el artículo 100 del Código penal y disposiciones vigentes, reduce no solamente las penas principales privativas de libertad, sino también las accesorias correspondientes a que se refieren los artículos 45,46 y 47 del referido cuerpo legal».

Dentro de la naturaleza jurídica de la redención de penas se plantea un segundo problema. Ya que mientras algunas referencias legales emplean el vocablo beneficio para referirse a la institución, otras veces, aunque las menos, se utiliza el término derecho. La doctrina se encuentra dividida, ya que mientras para algunos autores la redención de penas es una concesión graciosa de la Administración, argumentando, en apoyo de tal tesis, entre otros: a) que la palabra beneficio es la que ha venido empleando comunmente el legislador; b) su asimilación a la libertad condicional, en los primeros momentos, lo que hizo se atribuyese carácter condicional al tiempo redimido, o la idea de que la redención de penas era una especie de indulto concedido discrecionalmente, por tanto, por la Administración; c) el empleo del término podrán por parte del artículo 100 del Código penal que era interpretado como una potestad de la Administración que podía poner a redimir a los reclusos.

No obstante, estos argumentos carecen de solidez. La redención de penas por el trabajo constituye un auténtico derecho subjetivo del penado que cumpla los requisitos que establece el Código penal. Y ello, porque como mantiene BUENO ARUS(7): 1) la propia legislación repitió constantemente, hasta el Reglamento de los Servicios de Prisiones de 1948, las expresiones derecho a redimir, derecho al abono de redención, sin que el silencio posterior suponga una negación de tal carácter; 2) porque, si derecho subjetivo es una determinada situación de poder concreto concedida sobre cierta realidad social a una persona, en la redención de penas por 
el trabajo nos encontramos con una situación de poder concreto (los reclusos podrán redimir, según dice el artículo 100 del Código penal). El término podrán que emplean, tanto el artículo 100 del Código penal como el artículo 65 del Reglamento de los Servicios de Instituciones Penitenciarias, quiere decir que los rec/usos podrán redimir y no que la Administración podrá poner a redimir a los reclusos, como pretenden los partidarios del término beneficio. En definitiva, la redención de penas por el trabajo es un derecho subjetivo de aquellos penados que reunan los requisitos que señala el Código penal.

\section{2.-Evolución normativa.}

Los precedente históricos de la redención de penas por el trabajo se encuentran en el Código penal de 1822 (art. 144 y ss.), en la Ordenanza General de los Presidios del Reino de 1834 (art. 303 y ss.), en el Código penal de 1928 (art. 174) y en el Reglamento de los Servicios de Prisiones de 1930. ORTEGO COSTALES(8) ha llegado incluso a citar como precedente de la institución una Ley de los Reyes Católicos de 22 de junio de 1497. En todos estos Cuerpos legales el trabajo y la buena conducta daba lugar a un acortamiento de la condena. Asimismo, en otros países, principalmente Bulgaria, Noruega y en algunos Estados de Norteamérica (California, entre otros)(9), se admite la reducción de la condena por el trabajo.

Sin embargo, la redención de penas por el trabajo, tal y como la conocemos en la actualidad, nace en el transcurso de la guerra civil española de 1936-39 con una finalidad muy concreta: paliar los efectos de la contienda, aliviando las sobrecargadas prisiones y campos de concentración de prisioneros de guerra y condenados por delitos políticos. Algunos autores de la época, influidos por la pasión y el oportunismo político, olvidando los precedentes reseñados anteriormente afirmaron la originalidad de la institución atribuyendo su creación a una ocurrencia del General Franco(10). Falsa idea que tińo de tintes políticos partidistas para la posteridad a la redención de penas por el trabajo. Se implanta la redención de penas por Decreto $n .{ }^{\circ} 281$ de 28 de mayo de 1937 que, "concede el derecho al trabajo a los prisioneros de guerra y presos por delitos no comunesw(11). Por una 
Orden del Ministerio de Justicia de 7 de octubre de 1938 se crea un Patronato Central para la redención de penas por el trabajo, dependiente de la Jefatura del Servicio Nacional de Prisiones, asignándole, entre otras funciones, la de proponer al gobierno, al fin de cada año, la condonación de tantos dias de condena a favor de los reclusos que hayan trabajado como sea el número de días que hayan trabajado en efecto, con rendimiento real no inferior al de un obrero libre, y que además acrediten intachable conducta. En vista de los efectos beneficiosos que produjo, por Orden Ministerial de 14 de marzo de 1939 se amplía su concesión a los delincuentes comunes, excluyendo del derecho a redimir a quienes trataran de evadirse y los que cometieran un nuevo delito. El Decreto de 9 de junio de 1939 se dicta al objeto de conectar la redención de penas con la libertad condicional, adelantando la concesión de ésta en razón a la reducción operada en la pena como consecuencia del trabajo. La institución sería incorporada al Código penal de 1944, siendo aplicable a todo género de condenados con independencia del delito cometido(12). La redención solo era aplicada a las penas superiores a dos años de privación de libertad y se excluía de la misma: a los que hubieran disfrutado del beneficio en condenas anteriores; a los que quebrantaran la sentencia, logrando o no su propósito; los que no hubieran observado buena conducta durante la reclusión y los delincuentes en quienes concurriere peligrosidad social, a juicio del tribunal, expresamente consignado en la sentencia. La tendencia a ampliar la redención de penas comienza con la Orden Ministerial de 6 de febrero de 1956, que interpretando el artículo 100 del Código penal, dispone que la redención de penas reduce no solamente las penas principales privativas de libertad, sino también las accesorias correspondientes. El siguiente paso se daría aprovechando la reforma del Código penal de 28 de marzo de 1963: Se autoriza la redención para las penas superiores a seis meses, y se suprimen dos obstáculos para su concesión, el carácter de peligrosidad social y el de haber disfrutado del beneficio en condenas anteriores. Esta reforma supuso una ampliación considerable de la redención, ya que desde entonces se podía redimir desde los seis meses y un día, tiempo insuficiente para observar, clasificar, asignar puesto de trabajo y tramitar administrativamente la misma. BUENO ARUS(13) afirmaba que tal benevolencia legal es exagerada, en cuanto que se opone realmente a la finalidad preventiva de 
la institución y favorece su concesión automática. Paralelamente, el Reglamento Penitenciario de 1956, sufre dos modificaciones importantes: la primera, el 25 de enero de 1968 y la segunda, el 29 de julio de 1977. En ambas reformas se da una nueva redacción a determinados artículos del capítulo relativo a la redención de penas por el trabajo, ampliando, desde nuestro punto de vista, desmesuradamente, los efectos de la institución.

El siguiente estadio de la evolución normativa de la redención de penas por el trabajo, y a raíz de su exclusión del Proyecto de Ley Orgánica del Código penal de 1980, por haberse convertido, en opinión de MANZANARES ŞAMANIEGO(14), "en un elemento perturbador dentro de las nuevas concepciones penitenciarias o, si se prefiere, en una reliquia del pasado", el futuro de la institución es más que incierto. Tanto la Ley Orgánica General Penitenciaria de 1979 como el Reglamento Penitenciario de 1981 han eliminado de su articulado toda mención a la redención de penas por el trabajo, sustituyéndola por unos denominados beneficios penitenciarios, haciéndose patente de forma clara, a la vista de los preceptos que los regulan, que se trata, bajo nuestro punto de vista, de una especie de redención de penas por el trabajo encubierta, o disfrazada, como afirma DE LA MORENA VICENTE(15).

Pero como quiera que el artículo 100 del Código penal continuaba vigente, el Reglamento Penitenciario, no tuvo más remedio que establecer en su disposición transitoria segunda que, "no obstante lo dispuesto en la disposición derogatoria, a la entrada en vigor del Presente Reglamento, continuarán vigentes:

a) Los artículos 65 a 73 del Reglamento de los Servicios de Prisiones aprobado por Decreto de 2 de febrero de 1956, relativos a la redención de penas por el trabajo, en tanto continúe la vigencia de lo dispuesto en el artículo 100 del Código penal, texto refundido publicado por Decreto $3.096 / 1973$, de 14 de septiembre.

c) Los artículos 207 a 214, asimismo del Reglamento de 2 de febrero de 1956, relativos al Patronato Central de Nuestra Señora de la Merced, así como las disposiciones reguladoras de éste, que subsistirán hasta que se 
promulgue la normativa que regule la Comisión de Asistencia Social, creada por el artículo 74 de la Ley Orgánica General Penitenciaria y el personal de la misma".

A la vista de lo expuesto la situación es realmente compleja, confusa y hasta posiblemente ilegal, ya que, aunque provisionalmente, coexisten, la redención de penas por el trabajo, obedece a una vieja filosofía penal y penitenciaria, ya superada, y los beneficios penitenciarios, si bien producen los mismos efectos de acortamiento de la condena, tomando como base el desempeño de una actividad laboral, obedecen al principio de ejecución penal judicial, reconocido como postulado fundamental por la Ley Orgánica General Penitenciaria.

Así las cosas, en el Proyecto de Ley Orgánica de Reforma Parcial del Código penal de 1982 se da nueva redacción al artículo 100 introduciendo dos novedades que se podían considerar acertadas. De un lado, se atribuye expresamente a los Jueces de Vigilancia la aprobación de los beneficios de redención de penas por el trabajo con lo que se judicializa la institución. En segundo lugar, se extiende la redención, creemos que justamente, a quienes se encuentren en situación de prisión provisional siempre que hubieren estado trabajando. El artículo 100, en su primer párrafo, quedaba redactado de la siguiente manera: "Podrán redimir su pena por el trabajo, desde que sea firme la sentencia respectiva, los reclusos condenados a penas de reclusión y prisión. Al recluso trabajador se abonará, para el cumplimiento de la pena impuesta, previa aprobación del Juez de Vigilancia, un día por cada dos de trabajo, incluídos los realizados durante la prisión provisional y el tiempo así redimido se le contará también para la concesión de la libertad condicional». Con anterioridad, por medio de una proposión presentada por el Grupo Parlamentario de UCD, el 11 de abril de 1978, que llegó a ser dictaminado por la Comisión de Justicia el 25 de octubre de 1978 y aprobada en el Pleno del Congreso del 15 de noviembre, quedando pendiente en el Senado al concluir la legislatura, se pretendía suprimir el inciso "desde que sea firme la sentencia»; para abonar los días trabajados con efecto retroactivo a partir del día en que comenzo a trabajar, que pudo ser anterior al momento que la sentencia sea firme(16). 
3.-El artículo 100 del Código penal después de la reforma urgente y parcial de 1983.

El Proyecto de Ley de Reforma Urgente y Parcial del Código penal (Orgánica) publicado en el Boletín Oficial de las Cortes Generales, Congreso de los Diputados, II Legislatura, Serie A, número 10-I, de 25 de febrero de 1983, proponía como nueva redacción para el artículo 100 la siguiente:

«Podrán redimir su pena con el trabajo, desde que sea firme la sentencia respectiva, los reclusos condenados a penas de reclusión y prisión. Al recluso trabajador se abonará, para el cumplimiento de la pena impuesta, previa aprobación del Juez de Vigilancia, un día por cada dos de trabajo, y el tiempo así redimido se le contará para la concesión de la libertad condicional.

No podrán redimir penas por el trabajo:

1. ${ }^{\circ}$-Quienes quebranten la condena o intentaren quebrantarla, aunque.no lograren su propósito.

$2 .^{\circ}$ - Los que reiteradamente observen mala conducta dürante el cumplimiento de la condena".

El solo enunciado de esta propuesta de nueva redacción del artículo 100 del Código penal nos produjo la natural sorpresa, toda vez que si la Reforma Urgente y Parcial de nuestro Código punitivo se concebía como un anticipo de la promulgación de un nuevo Código penal donde no parece tener cabida, en opinión de gran parte de la doctrina, que no compartimos, la redención de penas, la institución que para MANZANARES SAMANIEGO17) es una reliquia del pasado, no sólo se resiste a desaparecer, sino que, paradójicamente, experimenta en los últimos tiempos un relanzamiento y una expansión inadmisibles cuando lo atinado en buena logica jurídica hubiese sido aprovechar la reforma para suprimir el artículo 100 del Código penal.

No obstante, el legislador, una vez más, y por razones de oportunidad político-penitenciaria, nos pone de relieve el fundamento de esta modificación en un fragmento de la Exposición de Motivos que acompaña a la reforma que comentamos: 
«Muchas son las críticas formuladas a la institución de la redención de penas por el trabajo, conocido es el origen de la misma y su supuesta orientación. El penitenciarismo moderno contempla el trabajo de los reclusos en el marco del tratamiento recuperador. Pero si bien un nuevo Código podrá abordar la transformación de esta institución, en el momento actual ello no parece posible porque sin previa modificación total de nuestro sistema de penas es difícil plantear la supresión de algo que, en función del sistema anterior, se plantea como beneficioso para el reo, lo cual, asi enfocado, resulta evidente».

La nueva redacción que inicialmente tenía el artículo 100 del Código penal al entrar en el Congreso de los Diputados ofrecía con respecto al texto anterior solamente una novedad, la de judicializar la institución: ".......previa aprobación del Juez de Vigilancia........". Novedad que para BUENO ARUS(18) resulta supérflua, ya que los Jueces de Vigilancia habían asumido íntegramente las competencias sobre la redención de penas por el trabajo desde su entrada en funcionamiento el 1 de octubre de 1981(19).

Al texto inicial del artículo 100 le fueron presentadas diversas enmiendas en el Congreso de los Diputados por todos los grupos parlamentarios. La incidencia de las mismas se centró en los siguientes aspectos:

1) Inclusión de la pena de arresto mayor junto a las de reclusión y prisión, con lo que se amplía el ámbito de aplicación de la redención, "para que no se produzca el absurdo de que una pena de seis meses y un día de prisión pueda suponer menos tiempo efectivo de prisión que una pena de seis meses", (Grupo Popular: enmienda $n .{ }^{\circ} 26$, Grupo Vasco: enmienda $n .{ }^{\circ}$ 299 y Grupo Mixto (Juan María Bandrés): enmienda $n .{ }^{\circ}$ 334).

2) Ampliación de los efectos de la redención a los internos que se encuentren en situación de prisión provisional, "ya que no puede recaer sobre los inculpados el notorio retraso en la celebración de los juicios", (Grupo Centrista: enmienda n. ${ }^{\circ} 123$, Grupo Socialista: enmiendas núms. 164 y 165, Grupo Minoría Catalana: enmienda.$^{\circ} 275$, Grupo Vasco: enmienda $n .{ }^{\circ} 300$ y Grupo Mixto (Juan María Bandrés): enmienda $n .{ }^{\circ} 334$.

La Ponencia, a la vista de las enmiendas presentadas, ofreció la siguiente redacción del artículo 100: 
"Podrán redimir su pena con el trabajo, desde que sea firme la sentencia respectiva, los reclusos condenados a penas de reclusión, prisión y arresto mayor. Al recluso trabajądor se abonará, para el cumplimiento de la pena impuesta, previa aprobación del Juez de Vigilancia, un día por cada dos de trabajo, y el tiempo así redimido se le contará también para la concesión de la libertad condicional. El mismo beneficio se aplicará, a efectos de liquidación de su condena, a los reclusos que hayan estado privados provisionalmente de libertad.

No podrán redimir pena por el trabajo:

$1 .^{\circ}$-Quienes quebranten la condena 0 intentaren quebrantarla, aunque no logreń su propósito.

$2 .^{\circ}$ - Los que reiteradamente observen mala conducta durante el cumplimiento de la condena".

El Pleno del Congreso de los Dipuitados en la sesión celebrada el 28 de abril de 1983 aprobó la redacción del artículo 100 del Código penal, tal y como había sido ofrecido por la Ponencia. Tras su paso, sin modificaciones, por el Senado el artículo 100 con su nueva redacción ha sido definitivamente promulgado según Ley Orgánica 8/1983, de 25 de junio, de Reforma Urgente y Parcial del Código penal (B.O.E. de 27 de junio).

A) Condiciones generales para su concesión. En la actualidad las normas aplicables a la redención de penas por el trabajo son el artículo 100 del Código penal y los artículos 65 a 73 del Reglamento de los Servicios de Instituciones Penitenciarias, de 2 de febrero de 1956, con las modificaciones posteriores (1968 y 1977). Artículos que continúan en vigor, según establece la disposición transitoria segunda del Reglamento Penitenciario de 1981. No obstante, algunos extremos de ese articulado penitenciario han quedado parcialmente modificados a partir de la nueva redacción del artículo 100 del Código penal.

$Y$ así, el primero de los preceptos reglamentarios citados, el artículo 65 , dispone, complementado y desarrollado lo dispuesto por el artículo 100 del Código penal, lo siguiente: 
«1. Conforme al artículo 100 del Código penal, podrán redimir su pena por el trabajo, desde que sea firme la sentencia, los condenados a penas de reclusión, presidio y prisión.

2. Igualmente podrán redimir todos cuantos, por aplicación de leyes especiales que no excluyan este beneficio, se encuentren privados de libertad por resolución firme, cuando el tiempo de privación exceda de seis meses.

3. No podrán redimir pena por el trabajo en la causa que se encuentren cumpliendo:

a) Quienes quebrantaren la condena o intentaren quebrantarla, aunque no lograren su propósito.

b) Los que reiteradamente observaren mala conducta durante el cumplimiento de la misma. Se entenderán comprendidos en este apartado los que cometieren nueva falta grave o muy grave sin haber obtenido la invalidación de las anteriores, conforme al artículo 116».

En este precepto hay que entender, dada la remisión que se hace al artículo 100 del Código penal que los penados que podrán redimir su pena por el trabajo serán, no sólo los condenados a penas de reclusión, presidio y prisión, como dice el texto reglamentario, sino que, de acuerdo con la nueva redacción del precepto penal los sentenciados a penas de arresto mayor pueden también beneficiarse de esta institución a partir de ahora.

B) Ambito de aplicación. La regla general es que pueden redimir pèna por el trabajo los condenados a penas privativas de libertad superiores a arresto mayor, es decir, desde un mes y un día en adelante. También podrán redimir, dice el artículo 66 del Reglamento Penitenciario, aquellos que se encuentren privados de libertad por aplicación de leyes especiales, siempre que: 1) el tiempo de privación sea superior a un mes y un día, 2) que la ley especial de referencia no excluya expresamente la aplicación de la redención, y, 3) que se encuentren privados de libertad por resolución firme. En todos los supuestos de redención es indiferente el grado penitenciario en que se encuentre el penado. 
En cuanto al trabajo, tiene que revestir alguna de las modalidades que menciona el artículo 68 del Reglamento: retribuido o gratuito, intelectual o manual, dentro o fuera de los establecimientos, pero en todo caso habrá de ser de naturaleza útil.

El precepto es de tal amplitud que resulta imposible que un penado dedicado a una actividad laboral pueda quedar excluído de la posibilidad de redimir su pena. De las modalidades de trabajo mencionadas en el artículo 68, el Reglamento únicamente desarrolla el realizado por esfuerzo intelectual, el cual podrá ser:

"1. ${ }^{\circ}$ - Por cursar y aprobar las enseñanzas religiosas o culturales establecidas y organizadas por el Centro Directivo.

$2 .^{\circ}$ - Por pertenecer a las agrupaciones artísticas, literarias 0 científicas del establecimiento penitenciario.

$3 .^{\circ}$-Por desempeñar destinos intelectuales.

$4 .^{\circ}-$ Por la realización de producción original, artística, literia o científican (art. 72).

Incluso recientemente se ha incluído la laborterapia como actividad laboral a efectos de redención para que los enfermos psíquicos y físicos puedan beneficiarse de la institución. En estos supuestos la Administración les facilitará los medios adecuados, debiendo ser el trabajo o actividad compatible con el estado de los internos (art. 71/4)(20).

C) Causas de incapacidad. Para que el penado pueda redimir su pena por el trabajo se requiere además que no se encuentre en alguna de las situaciones de incapacidad que legalmente se establecen: $10^{\circ}$ haber quebrantado o intentado quebrantar la condena, $2:^{\circ}$ los que cometieren una segunda falta grave o muy grave, sin haber obtenido la invalidación de la anterior 0 anteriores (arts. 100 del Código penal y 65 del Reglamento Penitenciario).

Con relación a la primera causa de incapacidad, DEL ROSAL(21), acertadamente afirmaba, que la encomiable institución de la redención de penas se empañaba en la redacción actual con la equiparación que se hace entre consumación del hecho, en el caso de quebrantar la condena, con el 
supuesto de intentarlo, en cuya valoración ha preponderado un criterio subjetivo que debiera de haberse salvado a toda costa(22).

La segunda causa de incapacidad, comisión de una falta grave o muy grave, sin estar invalidada la anterior, significa que la capacidad de redimir sigue subsistiendo con la comisión de una falta grave o muy grave, siendo intrascendente a estos efectos las faltas leves así como las faltas cometidas por los internos en situación de prisión preventiva. Estas causas de incapacidad para redimir están referidas a "la causa que se encuentren cumpliendon, por consiguiente, las causas de incapacidad para redimir no son de carácter permanente, sino que tienen que apreciarse concretamente en cada condena.

D) Iniciación. Aunque el anterior texto del artículo 100 del Código penal y el artículo 65 del Reglamento Penitenciario mencionaban como fecha para el comienzo del computo de tiempo redimido el de la firmeza de la sentencia, algunos autores, entre los cuales destacan BUENO ARUS(23) y RUIZ VADILLO(24), realizaban una interpretación progresiva deduciendo que el abono del tiempo redimido se retrotrae al tiempo en que el interno comenzó a trabajar, cualesquiera que fuese la situación procesal en que aquél se encontrase. Como afirma RUIZ VADILLO(25), de igual manera que la prisión preventiva sufrida por el delincuente antes de pronunciada la sentencia se cuenta para el cumplimiento de la condena (art. 33 del Codigo penal), entiendo que a quien trabaja durante esa prisión, si se dan los requisitos imprescindibles a toda redención, debe abonársele el trabajo efectuado en la forma establecida en el Código y en el Reglamento, de tal forma que al hacerse la correspondiente liquidación de condena se contarán como días de prisión preventiva los efectivamente sufridos como tal, más los redimidos por el trabajo. De esta manera, concluye el citado autor, podía decirse que, habiendo condena, la prision preventiva se hace pena y el trabajo, redención. Esta interpretación, a nuestro entender, se vio confirmada con ocasión de la reforma efectuada por el Real Decreto 2.273/1977, que dio nueva redacción al artículo 66 del Reglamento Penitenciario, suprimiendo, por un lado, la referencia a la firmeza de la sentencia, y disponiendo, por otro lado, que al recluso-trabajador, «le serán de abono los días trabajados, con carácter retroactivo, a partir del día en que dio comienzo el 
trabajo». En definitiva, todo penado tiene derecho al abono de redención a partir del día en que dio comienzo al trabajo, sin excluir el tiempo trabajado en la situación de prisión preventiva, siempre que se cumplan los demás requisitos previstos por el artículo 100 del Código penal.

Esta amplia interpretación que postulaba la doctrina ha recibido su consagración en'el nuevo texto del artículo 100 del Código penal, ya que la redención se aplicará "....a efectos de liquidación de su condena, a los reclusos que hayan estado privados provisionalmente de libertad".

E) Clases y efectos de la redención. Junto a la redención que podemos llamar ordinaria, regulada en el artículo 100 del Código penal y en el 66 del Reglamento, cuyo abono es de un día de condena por cada dos de trabajo, hay establecidas además en el Reglamento Penitenciario una serie de causas de redención extraordinaria, que con el transcurso del tiempo, y aprovechando las distintas y sucesivas reformas reglamentarias, sobre todo la de 1977, se han ido ampliando a límites que podíamos calificar de excesivos. Son las siguientes:

1.-Horas extraordinarias: "El trabajo que presten los penados en horas extraordinarias, o como destinos, o con carácter auxiliar y eventual en los establecimientos", computándose este trabajo, a efectos de redención, "por el número de horas que constituya la jornada legal de trabajo" (art. 71/1).

2.-Esfuerzos y riesgos extraordinarios: Serán valorados en días de trabajo, "con un límite de setenta y cinco días por cada año de efectivo cumplimiento", aquellos supuestos de esfuerzo realizado, "siempre con caráter absolutamente voluntario, por los donantes de sangre, así como el esfuerzo físico que un recluso realice o el riesgo que sufra auxiliando a las autoridades de un establecimiento penitenciario en circunstancias especiales" (art. 71/2).

3.-Circunstancias especiales: Las circunstancias especiales de, "laboriosidad, disciplina y rendimiento en el trabajo", también deberán valorarse en días de trabajo, "con el límite de uno por cada día de trabajo y de ciento setenta y cinco días por cada año de cumplimiento efectivo de la pena, compatible con lo establecido en el párrafo anterior" (art. 71/3). 
De esta manera, acumulando las diversas posibilidades de redención en un período de un año, un recluso puede redimir lo siguiente:

120 días de redención ordinaria (un día por cada dos de trabajo), (art. 66/1).

30 dias de redención por horas extraordinarias (art. 71/1).

75 días por donción de sangre o circunstancia similar (art. 71/2).

175 días por laboriosidad, o por alguno de los supuestos del art. 71/3.

El total redimido sería de 400 días, lo que vendrá a suponer que, en este supuesto, dicho recluso, durante el transcurso del año de trabajo habría extinguido 765 días de condena(26).

Durante el trámite parlamentario de la reforma del Código penal, una acertada enmienda de Juan Ramón Calero (Grupo Popular) pretendio, sin éxito, adicionar al artículo 100 la regulación contenida sobre las redenciones extraordinarias, tal y como se contemplan en el artículo $71 \mathrm{del}$ Reglamento Penitenciario. De otra forma, decía el parlamentario en su enmienda, la legalidad de estas redenciones extraordinarias serían más que dudosas por exceder de los límites del artículo 100 del Código penal. Es una lástima que no fuese aceptada esta enmienda, ya que, en nuestra opinión, actualmente la redención extraordianria, tal y como se regula reglamentariamente supone una ampliación excesiva de lo dispuesto en el artículo 100. Lo más razonable, por tanto, hubiese sido incorporar al Codigo las redenciones extraordinarias.

F) Supuestos excepcionales de redención sin actividad laboral. Los efectos de la redención no se interrumpirán, aunque el penado no tenga actividad laboral, en los siguientes supuestos:

1. Accidentes de trabajo o enfermedad: En estos casos, no se interrumpirá la redención, cualquiera que fuese "el tiempo que tarde el penado en curar y ser dado de alta, bien para realizar el mismo trabajo u otro de distinta naturaleza" (art. 70/1. ${ }^{\circ}$ ).

2. - Penadas gestantes: "Cuando se trate de penadas trabajadoras, que se encuentren en período de gestación, los sesenta días anteriores y cuarenta posteriores al alumbramiento, dispensándolas durante este tiempo de todo trabajon (art. 70/2. ${ }^{\circ}$. 
3. Días perdidos por cambios de destino o fuerza mayor: "Los días festivos, así como los días perdidos en el trabajo por fuerza mayor, destino a otro establecimiento o por razón de enfermedad suficientemente acreditada, siempre que no exceda en este último caso de treinta días consecutivos" (art. 70/3. ${ }^{\circ}$ ).

G) Pérdida de redención. Los casos de pérdida de la redención de penas por el trabajo, que establece el artículo 73 del Reglamento Penitenciario, son coincidentes, desde la reforma de 1977 , con los supuestos de incapacidad para redimir que fijan, tanto el artículo 100 del Código penal como el artículo 65 del Reglamento. En consecuencia, la redención de penas por el trabajo se perderá:

“1. Cuando realice intento de evasión, consiga o no su propósito. En este caso quedará inhabilitado para redimir en lo sucesivo.

2. Por la comisión de dos faltas graves o muy graves. El penado podrá ser rehabilitado y continuar redimiendo una vez que le haya sido invalidada de su expediente la anotación de la falta conforme al artículo 116 y previa aprobación del Patronato a propuesta de la Junta de Régimen.

Los dias ya redimidos serán computables para reducir la pena o penas correspondientes".

Sobre este precepto conviene hacer algunas precisiones: En el supuesto de pérdida de redención por evasión, intentada o consumada, el penado queda inhabilitado para redimir en lo sucesivo, por la misma condena, no por la sucesiva, si son varias las responsabilidades penales que tiene pendientes. En el supuesto de pérdida dé la redención por la comisión de dos faltas graves o muy graves, el penado puede seguir redimiendo por la misma condena siempre que se le invaliden las faltas disciplinarias que motivaron la pérdida de la redención. Es claro que, tanto en uno como en otro supuesto, para volver a redimir se requiere una nueva autorización del Patronato (ahora del Juez de Vigilancia), demostrativa de que el penado vuelve a poseer los requisitos legales para redimir. También se debe advertir que en ambos casos de pérdida de la redención, los días ya redimi- 
dos por el recluso no se pierden y son computables para reducir la pena 0 penas correspondientes.

H) Control judicial. En los supuestos de redención extraordinaria existía el control jurisdiccional de la institución, ya que aquéllas requerían, "el informe favorable del Tribunal Sentenciador, que lo emitirá después de oir al Ministerio Fiscal" (art. 71/4). Sin embargo, la reforma de 1977, que introdujo tan limitado control judicial no aprovecho la oportunidad para judicializar totalmente la redención, pues, a nuestro juicio, esta circunstancia ha venido siendo el obstáculo principal que tiene la institución para continuar subsistiendo dentro del contexto vigente. No puede olvidarse que la Ley General Penitenciaria reconoce como uno de sus principios fundamentales el de la ejecución penal judicial, que se concreta en la nueva figura del Juez de Vigilancia. Tal demanda no es nueva en la doctrina, pues DEL ROSAL(27), hace ya algunos años, decía que, la redención de penas por el trabajo, al igual que otras instituciones de prevención especial, debía ser aplicada por jueces de ejecución de penas, de cuyo organismo especializado estamos necesitados, y que funciona en la mayoría de los países con resultados excelente, en cuanto a la garantía que supone para el condenado.

La Dirección General de Instituciones Penitenciarias haciéndose eco de la opinión doctrinal mayoritaria favorable a la judicialización de la redención de penas e interpretando las facultades que el artículo 76/2, $\epsilon$. de la Ley General Penitenciaria otorgaba a los Jueces de Vigilancia, ordenó en una Circular de 7 de marzo de 1983 que: «.....todas las propuestas de redención de penas por el trabajo, con la documentación correspondiente, serán remitidas, en adelante, directamente, al Juez de Vigilancia.....».

Con la nueva redacción dada al artículo 100 del Código penal definitivamente se judicializa la institución, ya que para abonar la redención al recluso es necesario desde ahora la uprevia aprobación del Juez de Vigilancia». Durante el debate parlamentario de este artículo, una enmienda, que no prosperaría, de Juan María Bandrés (Grupo Mixto) pretendía suprimir la expresión previa aprobación del Juez de Vigilancia del párrafo primero ya que, según el parlamentario, al ser el derecho de redimir penas por el trabajo un derecho absoluto no puede condicionarse a la aprobación del 
órgano jurisdiccional, de modo que para su abono no ha de ser requerida aprobación alguna. Al mismo tiempo la enmienda adicionaba al párrafo segundo la mención "previa resolución motivada del Juez de Vigilancia", pues la denegación de penas por el trabajo, sí debe requerir resolución judicial motivada(28).

4. La redención de penas por el trabajo y los beneficios penitenciarios(29).

La redención de penas por el trabajo es una institución llamada a desaparecer, como hemos señalado anteriormente, debido, de un lado, a que el Proyecto de Ley Orgánica de Código penal de 1980 la excluye de su articulado, exclusión que por otra parte cuenta con el apoyo de un amplio sec. tor doctrinal y judicial. Las razones que justifican su desaparición vienen recogidas en la Exposición de Motivos de aquél, y son resumidamente las siguientes:

1. ${ }^{\circ} \quad$ La redención de penas había quebrantado el valor nominal de las penas, no sabiendo los Tribunales predecir de antemano cuánto tiempo iba a durar el cumplimiento efectivo de la sanción.

2. La redención de penas se producía de un modo casi automático, al margen de consideraciones de prevención especial y general, resultando la reducción de la condena impuesta en un tercio o más en la práctica totalidad de las penas privativas de libertad.

3. - La filosofía que inspira el Proyecto es que la pena recaída va a ser realmente cumplida bajo intervención judicial.

$4^{\circ} \quad$ La redención de penas se instaura en el Código de 1944 sobre la base del Decreto de 28 de mayo de 1937 aplicable a los presos políticos procedentes de guerra civil, por lo que desde el punto de vista políticocriminal es contraproducente, $y$, por tanto, debe desaparecer.

Los argumentos expuestos no admiten la más leve crítica, incluso se podría añadir, a nuestro juicio, que la redención de penas había alcanzado, sobre todo a raíz de la reforma de 1977, una expansión inadmisible, como hemos puesto de relieve con anterioridad, extensión que va en contra del 
principio de certeza relativa de las penas que se proclama en el moderno Derecho penal. Sin embargo, en favor de la institución, es conveniente y justo indicar que la redención de penas ha sido manipulada, sirviendo a la política penitenciaria de los distintos Gobiernos, de uno y otro signo, en cada momento histórico. Y así, en un primer estadio, el de su nacimiento, la redención de penas fue utilizada para solucionar los graves problemas de hacinamiento en los centros penitenciarios y en los campos de concentración, como consecuencia de la guerra civil española; en una segunda etapa, la redención de penas sirvió para acortar las penas excesivamente elevadas que imponían los Tribunales, de acuerdo con los preceptos de un Código penal (el de 1944), defensista, autoritario y riguroso, intentando tranquilizar de esta manera las conciencias de algunos; en una tercera etapa, la redención de penas en conexión con los consabidos indultos generales, sirvió para que los establecimientos penitenciarios no rebasasen una determinada cifra límite que permitía, de un lado, presumir hipocritamente ante el exterior de poseer el número de reclusos más bajo de Europa, y de otro lado, no dedicar ninguan atención presupuestaria a la construcción de nuevos establecimientos penitenciarios que sustituyesen a los viejos e inhóspitos caserones que se utilizaban como centros carcelarios. En la etapa de transición democrática, anterior a la presente, coincidiendo con la reforma del viejo Reglamento (1977), la redención de penas se utilizó como medio de aliviar las tensiones y las situaciones conflictivas del mundo prisional. En la actualidad, pese a los vientos contrarios a la institución, fruto de la reforma urgente y parcial del Código penal (Ley 8/1983, de 25 de junio), la redención es de nuevo relanzada por motivaciones políticas coyunturales, teniendo en cuenta la permanente conflictividad en que se desenvuelve la vida en los centros penitenciarios españoles.

Las cosas habían comenzado a complicarse con motivo de la entrada en vigor del Reglamento Penitenciario de 1981 al crear unos beneficios penitenciarios que tienen mucha similitud con la redención de penas por el trabajo, como más adelante tendremos ocasión de comprobar, aunque MANZANARES SAMANIEGO(30) afirme que son muy distintos los principios que inspiran a una y otra institución. En consecuencia, se produce una superposición entre la redención de penas y los beneficios penitenciarios que no tiene otra solución, a nuestro entender, que la paralización 
de la puesta en práctica de los beneficios penitenciarios, hasta que quede definitivamente suprimida la redención de penas. Para solucionar el problema, MANZANARES SAMANIEGO(31) propone hasta tres posibles vías: lo más correcto hubiese sido referirse expresamente a la redención de penas por el trabajo mediante disposición transitoria, pero no para mantener la vieja normativa, sino sometiendo aquella institución-en tanto subsistiera-a los nuevos principios de judicialización. Una segunda solución sería haberla regulado, a imagen de la libertad condicional, siguiendo, en todo caso, las directrices marcadas en cuanto a las funciones del Juez de Vigilancia concedidas en los artículos $76 / 1$ y $76 / 2$, a) y c), de la Ley General Penitenciaria. La tercera posibilidad de solución es la regulación de la redención dentro del título VI del Reglamento Penitenciario, como tercer beneficio-o primero-junto a los introducidos en sus artículos 256 y 257 , o dedicar a la redención de penas por el trabajo un título propio.

La solución que nos parece más conveniente, al objeto de evitar los problemas que puede generar la situaçión actual, es regular la redención de penas dentro del título VI que dedica el Reglamento Penitenciario a los beneficios penitenciarios, siempre que, como señalábamos anteriormente, se reconduzca la institución a unos límites razonables.

La Ley General Penitenciaria establece un sistema de recompensas que responde a unos criterios de política criminal diversos de los que motivaron el nacimiento de la redención de penas por el trabajo, tratando al mismo tiempo de que aquéllas no sean concedidas de manera automática, como de hecho viene sucediendo con la redención. En consecuencia, el artículo 46 de la Ley General Penitenciaria establece que, "los actos que pongan de relieve buena conducta, espíritu de trabajo y sentido de responsabilidad en el comportamiento personal y en las actividades organizadas del establecimiento serán estimulados mediante un sistema de recompensas reglamentariamente determinadon. Este principio general tiene su desarrollo en el Reglamento Penitenciario en los artículos 105 y 106, que ofrecen un catálogo de recompensas, y en los artículos 256 y 257 que contemplan los denominados beneficios penitenciarios(32).

Los artículos 105 y 106 se encuentran situados en el capitulo IX del título II, que lleva como rúbrica la de «Régimen disciplinario»(33), encuadra- 
miento lógico si tenemos en cuenta que la disciplina, elemento básico pa: ra garantizar la seguridad, el buen orden y conseguir una ordenada convivencia en los establecimientos penitenciarios, tiene que ir acompañada de un sistema equilibrado de recompensas o beneficios penitenciarios que actúen de estímulo y esperanza para aquellos internos que se hagan acreedores a ello. El artículo 105 dice lo siguiente:

"Los actos que pongan de relieve buena conducta, espíritu de trabajo y sentido de la responsabilidad en el comportamiento personal y en las actividades organizadas del establecimiento, serán estimulados con alguna de las siguientes recompensas:

a) Concesión de comunicaciones de carácter extraordinario.

b) Propuestas al Juez de Vigilancia a efectos de valoración por el mismo en la concesión de beneficios penitenciarios.

c) Premios en metálico.

d) Donación de libros y otros instrumentos de participación en actividades culturales y recreativas.

e) Notas meritorias, con anotación en el expediente personal del interno.

f) Cualquier otra de carácter análogo a las anteriores que, en compatibilidad con los preceptos reglamentarios, pudiera otorgarse".

La elección en cada supuesto de las recompensas y su extensión, "serán determinadas por la Junta de Régimen y Administración del establecimiento, atendiendo a las circunstancias objetivas y subjetivas, así como a la naturaleza de los méritos contraídos". "La concesión de recompensas será anotada en el expediente personal del interno, con expresión de los hechos que las motivaron" (art. 106)(34).

- Los beneficios penitenciarios son regulados en los artículos 256 y 257, únicos que constituyen el título VI del Reglamento Penitenciario. De tales preceptos se deduce que hay dos clases de beneficios, unos que podemos llamar ordinarios (art. 256), y otros extraordinarios (art. 257). 
Los beneficios penitenciarios ordinarios se conceden por el Juez de Vigilancia, de acuerdo con las facultades previstas en el artículo 76/2,c, de la Ley General Penitenciaria, previo estudio y acuerdo de los Equipos de Tratamiento, a través de las Juntas de Régimen y Administración de los establecimientos penitenciarios, consistiendo en una reducción de la condena de hasta cuatro meses de adelantamiento de la libertad condicional, por cada año de cumplimiento efectivo. El cómputo del tiempo adelantado se podrá realizar cada tres meses de prisión efectiva, correspondiéndole proporcionalmente un mes de reducción. El adelantamiento no tendrá ningún efecto con respecto a la libertad definitiva. La redención de penas sí puede producir una reducción parcial de la pena, sin tener que estar conectada con la libertad condicional.

Los requisitos necesarios que tienen que concurrir en los penados para hacerse acreedores al beneficio penitenciario son los siguientes:

«a) Buena conducta.

b) Desempeño de una actividad laboral normal, bien en el establecimiento o en el exterior, que se pueda considerar útil para su preparación para la vida en libertad.

c) Participación en las actividades de reeducación y reinserción social, organizadas en el establecimienton.

Los beneficios penitenciarios extraordinarios, se conceden a los penados en quienes concurran los mismos requisitos anteriores, "de modo continuado durante un tiempo mínimo de dos años y en un grado que se pueda calificar de extraordinario..... «En este caso el Juez de Vigilancia tramitará una solicitud de indulto particular, previo estudio y acuerdo del Equipo de Tratamiento, a través de la Junta de Régimen y Administración del centro penitenciario, que será de una cuantía de hasta udos meses por cada año de prisión efectiva...".

El análisis comparativo entre la redención de penas por el trabajo y los beneficios penitenciarios nos da como resultado que la actividad labo$\mathrm{ral}$ es el elemento esencial que sostiene ambas instituciones, y los efectos que producen, en cuanto a reducción de condena son coincidentes, tanto en la versión ordinaria como en la extraordinaria de las dos instituciones. 
Igualmente ambas se encuentran intervenidas judicialmente, de acuerdo con uno de los postulados fundamentales que inspiran la Ley General Penitenciaria: intervención judicial de la ejecución de la pena. La única diferencia que separa a las dos instituciones es que los beneficios penitenciarios requieren, aparte de buena conducta y trabajo, que el penado participe en su propio tratamiento (porque no puede querer indicar otra cosa el artículo 256/1, c): "participar en las actividades de reeducación y reinserción social, organizadas en el establecimienton), lo que parece contradictorio con las notas de voluntariedad que rodean el tratamiento penitenciario en nuestra legislación, principalmente el artículo 239/3 del Reglamento Penitenciario que afirma el derecho del interno de poder rechazar libremente o no colaborar en su tratamiento, sin que ello comporte consecuencias disciplinarias, ya que cacaso no existe una coacción sobre el interno para que acepte el tratamiento, sabiendo que si lo rechaza no estará en condiciones de conseguir los beneficios penitenciarios, y, en definitiva, la reducción de su condena(35).

En conclusión, podemos afirmar que nuestro criterio, ya expuesto a lo largo de estas páginas, es que la redención de penas por el trabajo, controlada por el Juez de Vigilancia, como a raíz de la última reforma se ofrece, y limitada a sus justos términos, sin excesos ni arbitrariedades de las que estuvo arropada en otros tiempos, puede seguir cumpliendo un digno papel de estímulo a los penados, dentro de los beneficios penitenciarios.

\section{NOTAS:}

(1) Acerca del tema vid., entre otros, ANTON ONECA, Derecho Penal. Parte General, Madrid, 1949, p. 517 y ss.; APARICIO LAURENCIO, El sistemá penitenciario español y la redención de penas por el trabajo, Madrid, 1954; AYLAGAS, El réglmen penitenciario español, Madrid, 1951, p. 83 y ss.; BUENO ARUS, "Panorama comparativo de los modernos sistemas penitenciarios", en Anuario de Derecho penal, 1969, p. 301 y ss.; BUENO ARUS, "La redención de penas por el trabajo en el Ordenamiento jurídico españolm; en Estudios penales y penitenciarios, Madrid, 1981; p. 161 y ss.; CORDOBA RODA, RODRIGUEZ MOURULLO, CASABO y DEL TORO, Comentarios al Código penal, Barcelona, 1972, p. 551 y ss.; DE LA MORENA VICENTE, "El trabajo y la redención de penas en Españan, en Revista de Estudios Penitenciarios n. ${ }^{\circ} 192$, enero- 
marzo 1971, p. 61 y ss.; DEL ROSAL, Tratado de Derecho Penal Español. Parte General, vol. II, Madrid, 1972, p. 647 y ss.; GARCIA VALDES, Régimen penitenciario en España, Madrid, 1975, p. 199 y ss.; GARRIDO GUZMAN, Compendio de Ciencia Penitenciaria, Valencia, 1976, p. 199 y ss.; LANDROVE DIAZ, Las consecuencias jurídicas del delito, 2. ${ }^{a}$ ed., Barcelona, 1983, p. 77 y ss.; LOPEZ RIOCEREZO, "Una aportación ejemplar: la redención de penas por el trabajọ, en Revista de Estudios Penitenciarios n. ${ }^{\circ}$ 156, enero-marzo 1962, p. 5 y ss.; UGALDE SANQUIRCE, "Sobre la naturaleza y efectos de la redención de penas", en Revista de Estudios Penitenciarios n. ${ }^{\circ} 119$, noviembre-diciembre 1955, p. 30 y ss.

(2) ANTON ONECA, ob. cit., p. 518. En el mismo sentido, CASTAÑEDA PEREZ, "La redención de penas, fórmula de indeterminación de la penan, en Revista de Estudios Penitenciarios n. ${ }^{\circ} 160$, enero-marzo 1963, p. 93 y ss.

(3) DEL ROSAL, J., Tratado de Derecho Penal Español. Parte General, vol. I, 3. a ed. (revisada y corregida por Manuel COBO), Madrid, 1979, p. 202.

(4) BUENO ARUS, «La redención de penas por el trabajo en el Ordenamiento jurídico espanol", en Estudios penales y penitenciarios, Madrid, 1981, p. 165.

(5) Vid. "Rectificación de un error", en Revista de Estudios Penitenciarios n. ${ }^{\circ} 142$, septiembre-octubre 1959, p. 1.510.

(6) BUENO-ARUS, ob. cit., p. 166.

(7) BUENO ARUS, "La suspensión o interrupción de la redención de penas por el trabajo", (separata), en Revista de Estudios Penitenciarios n. ${ }^{\circ}$ 208-211, 1975, p. 6 y ss.

(8) ORTEGO COSTALES, "EI trabajo en las prisiones", en Revista de Estudios Penitenciarios n. ${ }^{\circ} 55$, octubre 1949 , p. 8.

(9) Vid. TAFT, Criminology, $4 .^{\text {a }}$ ed., Nueva York y Londres, 1964, p. 533, da cuenta de que en el sistema de trabajos penales forestales de California se acredita a los trabajadores penados tres días de su condena por dos días de trabajo.

(10) Vid. AYLAGAS, ob. cit., p. 84; CUERVO, Fundamentos del nuevo sistema penitenciario español, Alcalá de Henares, 1941, p. 15 y PEREZ DEL PULGAR; La solución que España da al problema de sus presos políticos, Valladolid, 1939, p. 30.

(11) Vid. RODRIGUEZ DEVESA, Derecho Penal Español. Parte General, 8. a ed.; Madrid, 1981 , p. 909 y ss.

(12) Vid. FERRER SAMA, Comentarios al Código penal, II, Murcia, 1947, p. 355 y ss.

(13) BUENO ARUS, "El sistema penitenciario español", en Revista de Estudios Penitenciarios núms. 169-171, 1965, p. 201.

(14) MANZANARES SAMANIEGO, "Apuntes actuales sobre la redención de penas por el trabajon, en La normativa laboral penitenciaria, Primeras jornadas de trabajo del Organismo Autónomo "Trabajos Penitenciarios", Madrid, 1982, p. 289.

(15) DE LA MORENA VICENTE, "Situación y desarrollo de la normativa laboral penitenciaria», en La normativa laboral penitenciaria, cit., p. 202.

(16) Vid. BUENO ARUS, "La última modificación de la redención de penas por el trabajo", en Boletin de Información del Ministerio de Justicia $n .^{\circ} 1.156,25$ enero 1979, p. 3 y ss.

(17) MANZANARES SAMANIEGO, "La redención de penas por el trabajo en la actualidad", en Boletín de Información del Ministerio de Justicia n. ${ }^{\circ} 1.275,15$ mayo 1982, p. 3. 
(18) BUENO ARUS, "De nuevo sobre la redención de penas por el trabajo", en Cuadernos de Política Criminal n. ${ }^{\circ}$ 18, 1982, p. 433.

(19) Vid. GARCIA VALDES, Comentarios a la Legislación penitenciaria española, $2 .^{a}$ ed., Madrid, 1982, sobre todo, p. 249 y ss.

(20) Vid. en este mismo número de Anales el trabajo de CAMPS RUIZ, "La relación laboral penitenciaria» donde se expone una completa clasificación de las distintas modalidades de actividad laboral que los internos pueden realizar dentro o fuera de los establecimientos penitenciarios.

(21) DEL ROSAL, ob. cit., p. 208.

(22) Vid. GONZALEZ GUITIAN, «Dos problemas del artículo 334 del Codigo penal (En torno al delito de quebrantamiento de condena)m, en ESTUDIOS PENALES, II, La reforma penitenciaria, Santiago de Compostela, 1978, p. 275 y ss.

(23) BUENO ARUS, "El Real Decreto 2.273/1977 de 29 de julio y la redención de penas por el trabajon, en Cuadernos de Politica Criminal n. ${ }^{\circ} 3,1977$, p. 207.

(24) RUIZ VADILLO, "Comentarios a la reforma del Reglamento de.los Servicios de Instituciones Penitenciarias aprobada por Real Decreto de 29 de jullo de 1977", en Documentación Jurídica n. ${ }^{\circ} 15$, julio-septiembre 1977, p. 663.

(25) RUIZ VADILLO, ob. cit., p. 664.

(26) Vid. BUENO ARUS, ob. últimamente citada; p. 211 y RUIZ VADILLO, ob. cit., p. 661, con ejemplos de distintos supuestos de redención.

(27) DEL ROSAL; ob. cit., p. 208.

(28) Vid. ORTEGA LLORCA, "El Juez de Vigilancian, en Cuadernos de la Facultad de Derecho, 1-1982, Universidad de Palma de Mallorca, 1982, p. 191 y ss.

(29) Vid. BELLO LANDROVE, "La redención de penas y otros incentivos del trabajo penitenciario ante el futuro", en R.G.L.J. n. ${ }^{\circ}$ 2, febrero, 1979, p. 154; GARCIA ARAN, "Los nuevos beneficios penitenciarios: Una reforma inadvertidan, en Revista Juridica de Catalunya n. ${ }^{\circ} 1,1983$.

(30) MANZANARES SAMANIEGO, ob. cit., p. 290.

(31) MANZANARES SAMANIEGO, ob. cit., p. 291.

(32) Vid. GARCIA VALDES, "Relación del interno con la vida exterior y beneficios penitenciarios", en Cuadernos de Política Criminal n. ${ }^{\circ} 18,1982$, p. 599 y ss.

(33) En sentido crítico calificando de inoportunidad la denominación urégimen disciplina. rion que emplean, tanto la Ley como el Reglamento penitenciario, MAPELLI CAFFARENA, Principios fundamentales del Sistema Penitenciario Español, Barcelona, 1983, p. 294.

(34) Vid. GARCIA VALDES, Comentarios a la legislacción penitenciaria española, $2 .^{a}$ ed., Madrid, 1982, p. 141 y. ss.

(35) Vid. por todos BOIX REIG, J., "Aspectos de la Criminología en España" (separata) en Revista General de Derecho núms. 440-441, Valencia, mayo-junio, 1981, p. 18, para quien la voluntariedad en el tratamiento requlere de la ausencla de coerción al mismo, tanto directa como indirectamente, pues de lo contrario la posible manipulación de la personalidad del delincuente es obvia, sobre todo en la segunda de sus modalidades, la indirecta. 